\title{
Liquid and frozen multilayers of decanol in zeolites as microreactors for direct and oxygen mediated triplet-triplet annihilation of porphyrin
}

\author{
Peter P. Levin ${ }^{1,2, \dagger}$ and Silvia M. B. Costa ${ }^{1}$ \\ ${ }^{1}$ Centro de Quimica Estrutural, Complexo 1, Instituto Superior Tecnico, 1096 Lisbon Codex, Portugal \\ ${ }^{2}$ Russian Academy of Sciences, Institute of Biochemical Physics, Ulitsa Kosygina 4, 119991, Moscow, Russian Federation
}

\begin{abstract}
The kinetics of triplet state decay and concomitant delayed fluorescence of tetraphenylporphyrin (TPP) incorporated into the multilayers of n-decanol adsorbed on the external surface of zeolites at different temperatures were studied by the laser flash photolysis via monitoring the emission and diffuse-reflectance. In deoxygenated samples, the kinetics of diffusion-controlled bimolecular triplet-triplet annihilation (TTA) has been used to probe the multilayers. A very large local concentration of reactants may be obtained using small bulk amounts. A fast TTA rate constant demonstrated the triplet energy migration in TPP assemblies formed at the liquid/solid interface. The TTA in aerated samples is mediated by molecular oxygen leading to ${ }^{1} \mathrm{O}_{2}$ feedback-induced delayed fluorescence. Singlet oxygen works as an efficient mobile energy carrier between TPP triplets. The parameters of both TTA may be modified by multilayer, which acts as microreactor with supramolecular organization. The freezing of $n$-decanol results in dramatic apparent acceleration of both direct and ${ }^{1} \mathrm{O}_{2}$ mediated TTA due to the increase in local TPP concentration because of displacement of TPP molecules into the residual liquid domains in polycrystalline matrix. The concentration of TPP in those microreactors can be three orders of magnitude larger than the solubility limit in a particular neat liquid solvent demonstrating the unique features of solid solution, which seems to be due to the presence of crystal/liquid interfaces.
\end{abstract}

\section{INTRODUCTION}

Energy transfer processes of triplet excited states (T) at the interfaces are important in chemical, biological and technological areas. The well-known reaction between two triplet excited states is the triplet-triplet annihilation (TTA), which often results in delayed fluorescence due to the formation of the fluorescent singlet excited state by triplet-triplet energy transfer (TTADF). This process needs considerable amounts of $\mathrm{T}$ and may be achieved with strong laser pulse as an excitation source. The study of TTA kinetics at gas/solid and gas/liquid interfaces was carried out in order to probe the effect of surface topology, molecular diffusion, environment and organization [1-5]. The TTA requires molecular mobility of $\mathrm{T}$ which may be restricted by the adsorption and by the reaction space geometry. In this case TTA can be mediated by some mobile energy carrier available, e.g., by molecular oxygen. The ${ }^{3} \mathrm{O}_{2}$ quenching of $\mathrm{T}$ results in ${ }^{1} \mathrm{O}_{2}$ formation followed by singlet-triplet energy transfer from ${ }^{1} \mathrm{O}_{2}$ to second $\mathrm{T}$ (singlet oxygen feedback) generating the fluorescence. Our recent laser flash photolysis investigation of ${ }^{1} \mathrm{O}_{2}$ feedbackinduced delayed fluorescence (SOFDF) from porphyrins and eosin at gas/solid and gas/liquid interfaces showed that SOFDF kinetics can provide kinetic parameters of the ${ }^{1} \mathrm{O}_{2}$ excitation migration at the interface and some information about supramolecular organization [5-9].

\footnotetext{
${ }^{\dagger}$ E-mail: levinp@sky1.chph.ras.ru
}

Here we report the laser flash photolysis study of meso-tetraphenylporphyrin (TPP)- $\mathrm{O}_{2}$-n-decanol-NaA zeolite system with complementary analysis of ground state absorption and steady-state emission in comparison with the corresponding behavior of TPP adsorbed onto the dry external surface of NaA zeolite and in the bulk of $n$-decanol. While ${ }^{1} \mathrm{O}_{2}$-feedback is the only pathway of TTA on dry surface, both SOFDF and TTADF can occur in n-decanol and on the zeolite surface covered by n-decanol multilayers. The kinetic analysis of TTA, TTADF and SOFDF shows that multilayers of $n$-decanol on external zeolite surface may be used as controlled size microreactors with supramolecular organization. It is found that the freezing of $\mathrm{n}$-decanol is accompanied by concentration of TPP in some liquid domains in polycrystalline matrix and apparent acceleration of both direct and ${ }^{1} \mathrm{O}_{2}$ mediated TTA is observed. The local concentration of TPP in those domains of solid solution is orders of magnitude larger than the solubility limit in liquid n-decanol, which seems to demonstrate the specific feature of crystal/liquid interfaces.

\section{MATERIALS AND METHODS}

2.1. Materials. TPP (from Hambright, Washington, DC) was purified by recrystallization from methanol. The sodium form of zeolite $\mathrm{A}$ ( NaA, Aldrich, $\mathrm{Si} / \mathrm{Al}=$ 1.0 , crystallite particle size $1-2 \mu \mathrm{m}$ was controlled by electron microscopy, estimated external surface area $\left.3 \mathrm{~m}^{2} / \mathrm{g}[6,7]\right)$ was dried in a vacuum at $\approx 150^{\circ} \mathrm{C}$ for 
$48 \mathrm{~h}$ prior to use. Benzene (Aldrich, spectrophotometric grade) was dried over $\mathrm{P}_{2} \mathrm{O}_{5}$ and then used as solvent for the TPP and n-decanol. The purity of n-decanol (Fluka, puriss., m. p. $6.4^{\circ} \mathrm{C}$ ) was checked by zone melting.

2.2. Sample preparation. The solutions $(3-5 \mathrm{~mL})$ of TPP in benzene with various amounts of n-decanol were added to NaA samples $(1 \mathrm{~g})$. The suspensions were stirred during evaporation at $20^{\circ} \mathrm{C}$. It was found that up to $0.35 \mathrm{~mL}$ of $\mathrm{n}$-decanol can be loaded onto $1 \mathrm{~g} \mathrm{NaA}$ and the sample does not exhibit a distinguishable liquid macrophase. This n-decanol amount corresponds to 300 monolayers (one monolayer is $1.2 \mu \mathrm{L} / \mathrm{g}$, assuming $0.5 \mathrm{~nm}$ radius of $\mathrm{n}$-decanol molecule). The large TPP and n-decanol molecules are located at the external surface of NaA crystallites, which internal network is characterized by small windows of diameters $0.4 \mathrm{~nm}[5,10]$. Samples were evacuated by freeze pump procedure up to $1 \times 10^{-3}$ torr. Selected amounts of air in the sample cell were obtained from a system of calibrated volumes. Samples were thermostated with accuracy $\pm 1{ }^{\circ} \mathrm{C}$ in water or ethanol bath.

2.3. Instrumentation and data analysis. The description of steady-state spectrophotometer, spectrofluorimeter and diffuse reflectance laser flash photolysis was given earlier [6-9]. Ground state and transient reflectance of solid samples were analysed in terms of Kubelka-Munk theory $\triangle \mathrm{F}=(1-\mathrm{R})^{2} / 2 \mathrm{R}-$ $\left(1-\mathrm{R}^{\prime}\right)^{2} / 2 \mathrm{R}^{\prime}$ or $\triangle \mathrm{F}_{\mathrm{t}}=\left(1-\mathrm{R}_{\mathrm{t}}\right)^{2} / 2 \mathrm{R}_{\mathrm{t}}-(1-\mathrm{R}) 2 / 2 \mathrm{R}$, respectively, where $R$ and $R^{\prime}$ are diffuse reflectance from the surface of the samples with and without TPP, respectively, and $R_{t}$ is the reflectance observed at time $t$ after the laser pulse [1-3]. The validity of KubelkaMunk treatment for analysis of transient decays in the present system was confirmed earlier [5-9].

\section{RESULTS AND DISCUSSION}

3.1. Effect of liquid/solid interface on the ground state absorption and prompt fluorescence of TPP. The Soret band of TPP absorption on the surface of dry $\mathrm{NaA}$ at small loadings is much broader and blue shifted in comparison with that in n-decanol (Figure 1) [7]. The broadening of the absorption bands reflects the inhomogeneous environment of the adsorbed molecules on the surface $[6,11]$. The blue shift of TPP Soret band was attributed to the relatively small apparent value of the refractive index for the medium where TPP is localized on gas/solid interface $[5,9]$. The transition from the gas/solid to liquid/solid interface with coadsorption of small amounts of n-decanol on the NaA external surface results in narrowing and red shift of the TPP Soret band maxima which is larger than that in pure n-decanol (Figure 1). Further increase of n-decanol amount in the samples with small TPP content leads to further narrowing but to a blue shift of TPP Soret band

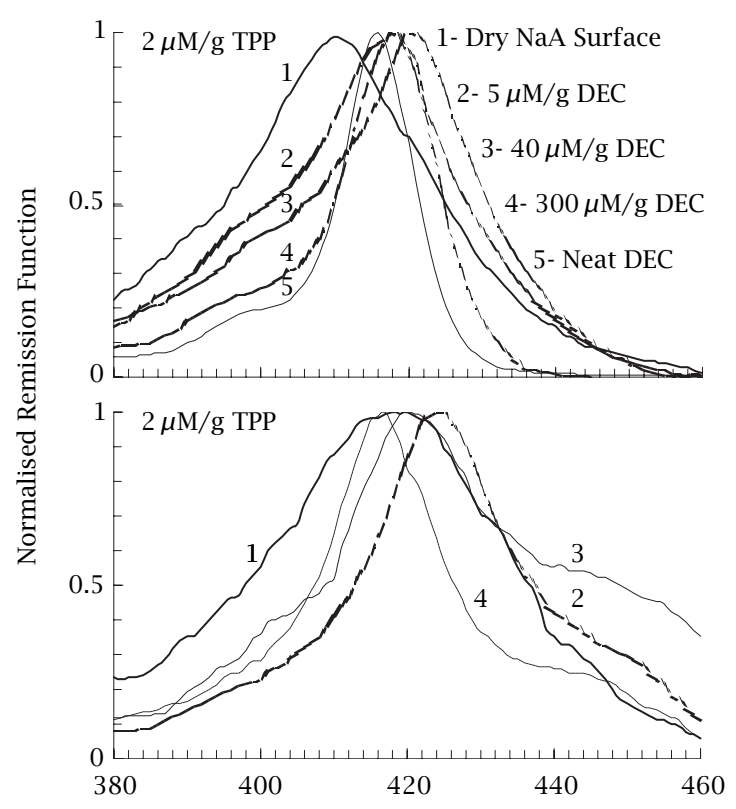

Figure 1. Normalized reflectance spectra of NaA solid samples plotted using the differences in remission function with 0.05 (up) and 2 (down) $\mu \mathrm{mol} / \mathrm{g}$ TPP on dry surface (1), with coadsorbed $5 \mu \mathrm{L} / \mathrm{g}$ (2), $40 \mu \mathrm{L} / \mathrm{g}$ (3) and $300 \mu \mathrm{L} / \mathrm{g}$ (4) $n$-decanol (DEC) and in liquid n-decanol (5) (in terms of optical density).

which becomes practically identical to that in n-decanol if the ratio of TPP/n-decanol in the sample is smaller than $0.1 \mathrm{mmol} / \mathrm{L}$ which corresponds to the solubility of TPP in n-decanol [5].

Increase of TPP concentration in dry NaA samples over $0.1 \mu \mathrm{mol} / \mathrm{g}(0.1 \mu \mathrm{mol} / \mathrm{g}$ corresponds to $5.7 \%$ of a TPP monolayer on the surface if the size of TPP molecule is taken to be equal to TPP long axis, $1.9 \mathrm{~nm}$ [12]) results in a red shift and broadening of Soret band, indicating aggregation of TPP on the surface (Figure 1) $[6,7]$. The addition of n-decanol to concentrated TPP solid samples results in the appearance of a broad shoulder at 440-450 nm (Figure 1) which shows the formation of some new type of TPP aggregates in the liquid microphase or at the liquid/solid interface [5]. The aggregates were not observed in neat n-decanol solutions of TPP.

The fluorescence spectrum of TPP on dry surface of $\mathrm{NaA}$ is similar in most features to that in n-decanol with the exception of some broadening and small shift of vibronic bands near 650 and $720 \mathrm{~nm} \mathrm{[5,7].} \mathrm{The} \mathrm{flu-}$ orescence quantum yield $\left(\varphi_{\mathrm{FL}}\right)$ and lifetime $\left(\varphi_{\mathrm{FL}}\right)$ on dry NaA surface $(0.076$ and $8.6 \mathrm{~ns}$, respectively) are insignificantly smaller than those in solution (values 0.12 and $12.5 \mathrm{~ns}$, respectively, in the deoxygenated n-decanol) [7]. The coadsorption of n-decanol results in a gradual change of the TPP prompt fluorescence parameters to those observed in liquid n-decanol [5]. 
The rate constant of TPP prompt fluorescence quenching by $\mathrm{O}_{2}$ on $\mathrm{NaA}$ surface with coadsorbed monolayer of n-decanol is twenty times smaller than that on dry surface $\left(2.4 \times 10^{10} \mathrm{~L} \mathrm{~mol}^{-1} \mathrm{~s}^{-1}\right)$ due to the screening effect. Further increase of n-decanol content in the sample results only in insignificant $\tau_{\mathrm{FL}}$ increase in oxygenated solid samples to that in oxygenated ndecanol solution, where the corresponding quenching rate constant was estimated as $5.4 \times 10^{9} \mathrm{~L} \mathrm{~mol}^{-1} \mathrm{~s}^{-1}$ [5].

3.2. Direct triplet-triplet annihilation of TPP at liquid/solid interface. Photoexcitation of TPP on the surface and in solution produces the well-known $[7,9,13,14]$ transient differential spectra of ${ }^{3}$ TPP with strong bleaching at the wavelength of Soret band and maximum absorption near $440 \mathrm{~nm}$. A comparison of triplet-triplet absorption (measured immediately after the laser pulse, $\triangle F_{t}=0$, at high laser fluence and small surface loading when transient signal intensities are in saturation) with initial ground state absorption show a large efficiency of ground state conversion to the triplet state (> 50\%). The $80 \%$ value was measured for the diluted solutions of TPP in n-decanol (using literature values of corresponding extinction coefficients [12-14]), which coincides with the ${ }^{3} \mathrm{TPP}$ quantum yield, $\varphi_{\mathrm{T}}=0.8$ $[12,15]$. For concentrated samples, the initial concentration of triplets $\left([\mathrm{T}]_{0}\right)$ was estimated by comparison of $\triangle F_{t}=0$ and the prompt fluorescence yield (Y $\mathrm{Y}_{\mathrm{PF}}$, an amount of light emitted during prompt fluorescence) with those measured for similar diluted samples.

The mean lifetime of ${ }^{3}$ TPP in evacuated samples of dry $\mathrm{NaA}$ is around $1 \mathrm{~ms}$ and depends neither on sample loading nor on the initial ${ }^{3}$ TPP concentration [7]. In the presence of $n$-decanol on the NaA surface in deoxygenated solid samples, the TTA becomes the most important pathway of ${ }^{3} \mathrm{TPP}$ decay if the local ${ }^{3} \mathrm{TPP}$ concentration is large enough [5]. The ${ }^{3}$ TPP decay kinetics shows the clear second order behavior. The significant acceleration of ${ }^{3}$ TPP mobility in the presence of $\mathrm{n}$-decanol is related to the fast adsorption - desorption process and desorbed ${ }^{3}$ TPP diffusion in the liquid-like microphase [5]. A strong TTADF was detected with a spectral pattern similar to that of prompt and steady state fluorescence. The kinetic Scheme 1 and corresponding equations (1) and (2) ( $\mathrm{I}_{\mathrm{TTADF}}$ and $\mathrm{Y}_{\mathrm{TTADF}}$ are the TTADF intensity and yield, respectively) obtained in steady state

$$
\begin{aligned}
& \frac{[\mathrm{T}](t)}{[\mathrm{T}]_{0}}=\frac{\mathrm{k}_{0} \exp \left(-\mathrm{k}_{0} t\right)}{\mathrm{k}_{0}+\mathrm{k}_{\mathrm{OBS}}[\mathrm{T}]_{0}\left\{1-\exp \left(-\mathrm{k}_{0} t\right)\right\}}, \\
& \text { where } \mathrm{k}_{\mathrm{OBS}}=\mathrm{k}_{\mathrm{DIF}} \frac{5-\varphi_{\mathrm{T}}}{9} \\
& \mathrm{I}_{\mathrm{TTADF}}(t)=\mathrm{k}_{\mathrm{RAD}}\left[\mathrm{S}_{1}\right]=\varphi_{\mathrm{FL}} \frac{1}{9} \mathrm{k}_{\mathrm{DIF}}\{[\mathrm{T}](t)\}^{2} \\
& \text { and } \frac{\mathrm{Y}_{\mathrm{TTADF}}}{\mathrm{Y}_{\mathrm{PF}}}=\frac{\varphi_{\mathrm{T}}}{5-\varphi_{\mathrm{T}}}
\end{aligned}
$$

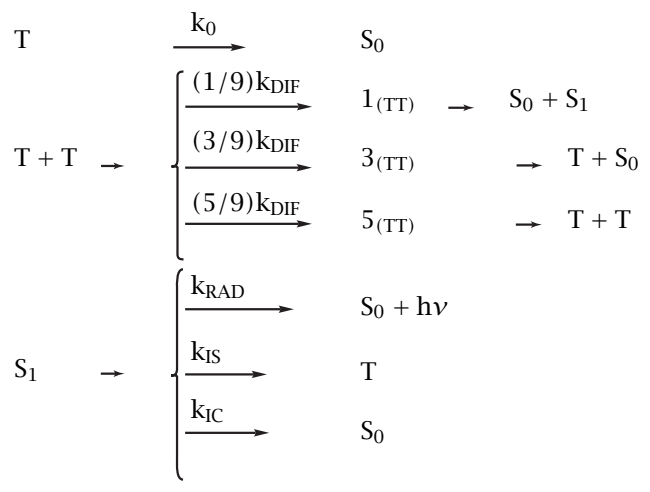

Scheme 1.

approximation $\left(d\left[\mathrm{~S}_{1}\right] / d t=0\right)$ are able to quantify ${ }^{3} \mathrm{TPP}$ and TTADF kinetics $[5,16,17]$. A perfect fit of the ${ }^{3}$ TPP and TTADF decay kinetics to Scheme 1 was obtained for n-decanol solutions and for solid samples (Figure 2), supporting the idea that TTA takes place in relatively homogeneous n-decanol microphase.

In n-decanol solutions, the extracted value of $\mathrm{k}_{\mathrm{OBS}}$ near $1.9 \times 10^{8} \mathrm{~L} \mathrm{~mol}^{-1} \mathrm{~s}^{-1}\left(20^{\circ} \mathrm{C}\right)$ corresponds to $k_{\text {DIF }}=4.0 \times 10^{8} \mathrm{~L} \mathrm{~mol}^{-1} \mathrm{~s}^{-1}$ if $\varphi_{\mathrm{T}}=0.8$ which is very close to the diffusion-controlled limit $[5,16]$. The TTA of TPP is a diffusion-controlled process with spin statistic restrictions [17]. In diluted solid samples with large amount of $n$-decanol when the ratio of TPP/n-decanol

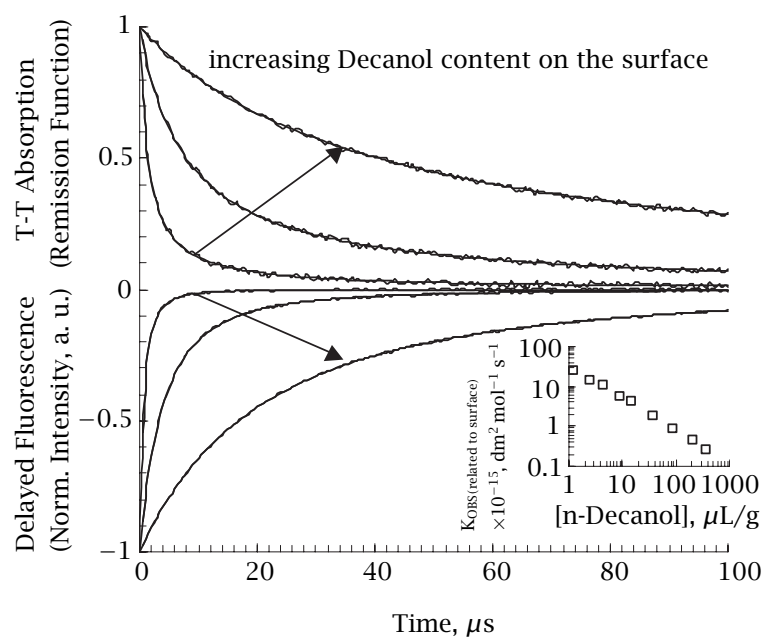

Figure 2. Normalized decays of the transient remission function change measured at $450 \mathrm{~nm}$ and transient emission at $720 \mathrm{~nm}$ with $0.02 \mu \mathrm{mol} / \mathrm{g}$ TPP deoxygenated samples of $\mathrm{NaA}$ with coadsorbed 2, 30 and $200 \mu \mathrm{L} / \mathrm{g}$ n-decanol. Lines are the best fitting to corresponding equations (1) and (2). Inset shows the dependence of TTA rate constant related to the surface area, $\mathrm{k}_{\mathrm{OBSS}}$, on $n$-decanol concentration. 


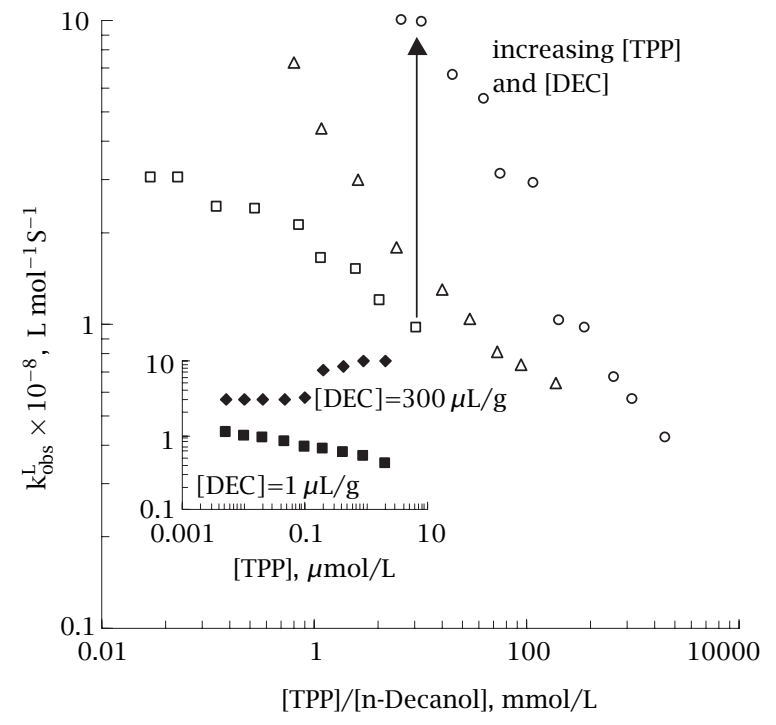

Figure 3. Dependence of TTA rate constant related to the $n$-decanol volume, $\mathrm{k}_{\mathrm{OBS}}^{\mathrm{L}}$, on [TTA]/[n-decanol] varied by changing the n-decanol content ([DEC]) in the solid $\mathrm{NaA}$ samples with $0.005(\square), 0.1(\triangle)$ and $1(\bigcirc) \mu \mathrm{mol} / \mathrm{g} T P P$. Inset shows the dependence of $\mathrm{k}_{\mathrm{OBS}}^{\mathrm{L}}$ on surface loading in $\mathrm{NaA}$ samples with 300 and $1 \mu \mathrm{L} / \mathrm{g}$ of $n$-decanol.

is smaller than $0.1 \mathrm{mmol} / \mathrm{L}$ (solubility of TPP in $\mathrm{n}$ decanol), the value of $\mathrm{k}_{\mathrm{OBS}}=2.5 \times 10^{8} \mathrm{~L} \mathrm{~mol}^{-1} \mathrm{~s}^{-1}$, calculated using the volume of n-decanol in the sample as a reaction space, is similar to that in neat n-decanol and independent on n-decanol content and TPP concentration. The value of $\mathrm{k}_{\mathrm{OBS}}$ decreases with the increase in [TPP]/[n-decanol] in the region where [TPP]/[n-decanol] is larger than $0.1 \mathrm{mmol} / \mathrm{L}$ (Figure 3) showing the transition from the reaction in the bulk of n-decanol microphase to the process which involves adsorption-desorption equilibrium.

However, a very fast TTA was found in the presence of new type of TPP aggregates (see above) in the samples with high TPP and n-decanol content (Figure 3). The corresponding values of $\mathrm{k}_{\mathrm{OBS}}$ can be one order of magnitude larger than those measured at small TPP concentration. The triplet energy migration within these TPP aggregates in n-decanol microphase or at the liquid/solid interface seems to be responsible for the acceleration of triplet excitation mobility. One may suppose, that the liquid/solid interface facilitate some supramolecular organization of reactants which induce fast triplet excitation migration neither available in homogeneous solution nor on dry surfaces.

The TTADF relative yield ( $\left.\mathrm{Y}_{\mathrm{TTADF}} / \mathrm{Y}_{\mathrm{PF}}\right)$ in n-decanol solution or in n-decanol multilayers when triplets are in n-decanol microphase and there is no TPP aggregates is close to $20 \%$ in accordance with that predicted by Scheme 1 if $\varphi_{\mathrm{T}}=0.8$. The $\mathrm{Y}_{\mathrm{TTADF}} / \mathrm{Y}_{\mathrm{PF}}$ value decreases (down to $5 \%$ ) for samples where triplets are adsorbed on the surface or TPP aggregates are involved. This finding implies some variation in TTA mechanism and/or quenching of TPP singlet excited state at the liquid/solid interface and in TPP aggregates in comparison with those in the bulk of liquid phase.

\subsection{Oxygen mediated triplet-triplet annihilation} of TPP at liquid/solid interface. A monoexponential ${ }^{3}$ TPP decay kinetics was found in aerated solid samples of TPP on NaA with coadsorbed n-decanol when the contribution of TTA was small. The ${ }^{3}$ TPP is quenched by ${ }^{3} \mathrm{O}_{2}$ in the presence of one $\mathrm{n}$-decanol monolayer on the surface 20 times slower than on dry NaA surface $\left(6.3 \times 10^{9} \mathrm{~L} \mathrm{~mol}^{-1} \mathrm{~s}^{-1}\right.$ [7]). Further increase of n-decanol content results in the insignificant decrease of $\mathrm{k}_{\mathrm{q}}$ which becomes equal to the value found in neat n-decanol. Similar effects were observed for $\mathrm{O}_{2}$ quenching of prompt fluorescence (see above). The rate constant of ${ }^{3}$ TPP quenching by $\mathrm{O}_{2}$ in neat $\mathrm{n}$-decanol $(9.4 \times$ $10^{8} \mathrm{~L} \mathrm{~mol}^{-1} \mathrm{~s}^{-1}$ ) is only $1.5-3$ times smaller than $\mathrm{k}_{\mathrm{q}}$ reported for nonviscous solvents $[18,19]$. Taking into account that this process is expected to be characterized by spin-statistical factor $1 / 9$ (quenching of ${ }^{3} \mathrm{TPP}$ by ${ }^{3} \mathrm{O}_{2}$ in solution results in ${ }^{1} \mathrm{O}_{2}$ formation with $80-90 \%$ efficiency $[18,19])$ one may conclude that the value of diffusion-controlled reaction with the participation of $\mathrm{O}_{2}$ in n-decanol seems to be more than one order of magnitude larger than $\mathrm{k}_{\mathrm{DIF}}$.

The high mobility of $\mathrm{O}_{2}$ gives a possibility of energy carriage between TPP triplets. The SOFDF can be readily detected in the presence of $\mathrm{O}_{2}$ in both solid NaA samples and in n-decanol $[5,7]$. The corresponding delayed fluorescence kinetic curves contain the rising part followed by the decay with lifetime of the ${ }^{3} \mathrm{TPP}$, making a difference for kinetics of direct TTADF (Figure 4). The relative yield of SOFDF ( $\mathrm{Y}_{\mathrm{SOFDF}} / \mathrm{Y}_{\mathrm{PF}}$ ) from air saturated solid samples of TPP with n-decanol or in air saturated n-decanol solutions does not exceed 2\%. ( $\mathrm{Y}_{\mathrm{SOFDF}} / \mathrm{Y}_{\mathrm{PF}} \mathrm{up}$ to $15 \%$ is observed in dry NaA samples [7]). However, the peak intensity of this delayed fluorescence is larger than that from direct TTA.

The fitting of SOFDF kinetic curves to corresponding equation (3) derived for Scheme 2 gives

$$
\begin{aligned}
\frac{\mathrm{I}_{\mathrm{TTADF}}{ }^{(t)}}{\mathrm{Y}_{\mathrm{PF}}}= & \alpha \mathrm{k}^{\mathrm{SO}} \frac{\left[\left(\mathrm{S}_{1},{ }^{3} \mathrm{O}_{2}\right)\right]}{[\mathrm{T}]_{0}} \\
= & \alpha \mathrm{k}_{\mathrm{q}}\left[\mathrm{O}_{2}\right] \exp \left(-k_{q}\left[\mathrm{O}_{2}\right] t\right) \times \\
& \times\left\{1-\exp \left[\frac{\mathrm{k}_{\mathrm{q}}^{1}[\mathrm{~T}]_{0}}{\mathrm{k}_{\mathrm{q}}\left[\mathrm{O}_{2}\right]}\left(\exp \left(-\mathrm{k}_{\mathrm{q}}\left[\mathrm{O}_{2}\right] t\right)-1\right)\right]\right\}
\end{aligned}
$$

the parameter $\mathrm{k}_{\mathrm{q}}^{1}[\mathrm{~T}]_{0}$. and the maximum value of $\mathrm{Y}_{\mathrm{SOFDF}} / \mathrm{Y}_{\mathrm{PF}}\left(\alpha=\left(\varphi_{\mathrm{FL}}\right.\right.$ so $\left./ \varphi_{\mathrm{FL}}\right) \varphi_{\mathrm{T}}$, where $\varphi_{\mathrm{FL}}$ so is the quantum yield of fluorescence from the couple $\left(\mathrm{S}_{1},{ }^{3} \mathrm{O}_{2}\right)$ ) which can be observed at optimal $\left[\mathrm{O}_{2}\right]$ and $[\mathrm{T}]_{0}$ [5-9]. In order to obtain the reliable values of $k_{q}^{1}$, 


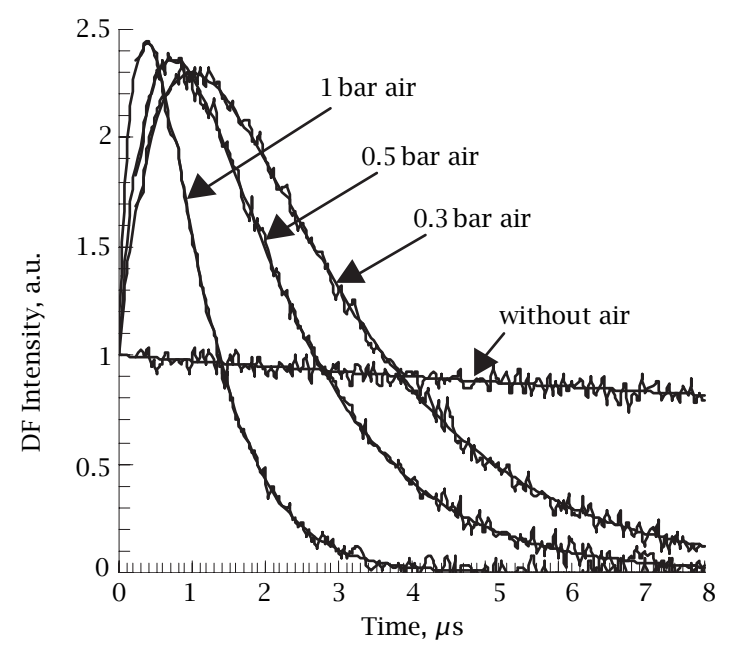

Figure 4. Decays of the transient emission at $720 \mathrm{~nm}$ measured with $0.02 \mu \mathrm{mol} / \mathrm{g}$ TPP and $100 \mu \mathrm{L} / \mathrm{g} \mathrm{n}$-decanol in the solid NaA samples at air pressure 1, 0.5, 0.3 bar and without air.

the simultaneous fitting of 5-10 kinetic curves of SOFDF measured with a given sample loading, but at different oxygen pressures (global kinetic analysis), was carried out using common values of $\alpha$ for all delayed fluorescence curves [5-9]. In n-decanol solutions or in diluted solid samples with large n-decanol amount (all ${ }^{3}$ TPP assumed to be in the $\mathrm{n}$-decanol microphase), this procedure gives the value of $\alpha$ equal to $8 \%$ and $\mathrm{k}_{\mathrm{q}}^{1}$ near $9 \times 10^{9} \mathrm{~L} \mathrm{~mol}^{-1} \mathrm{~s}^{-1}$ which is, as one should expect, an order of magnitude larger than the $\mathrm{k}_{\mathrm{q}}$ value. The value of $\alpha$ (the efficiency of singlet oxygen feedback) in ndecanol is only insignificantly smaller than value of $\alpha$ obtained at gas/solid interface ( $\alpha$ increases from 11 to $15 \%$ with surface loading), showing that the difference between the efficiencies of $\left(\mathrm{S}_{1},{ }^{3} \mathrm{O}_{2}\right)$ primary couple

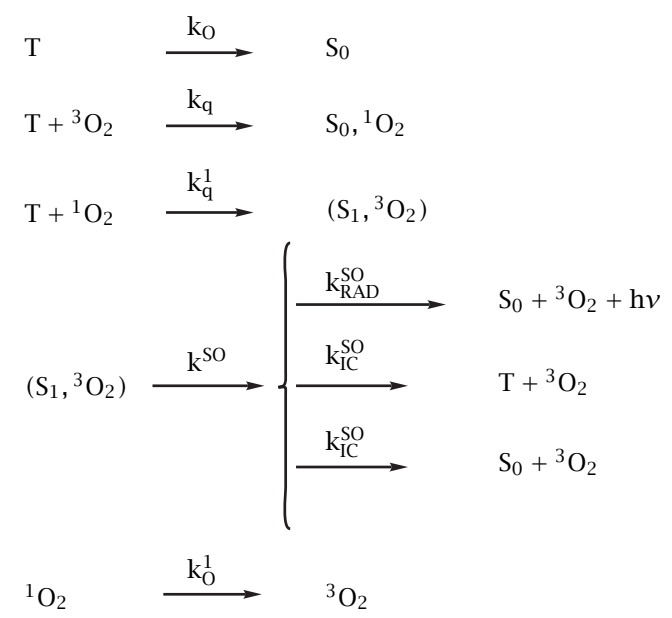

Scheme 2. separation in n-decanol and at gas/solid interface is not pronounced $[8,9]$. The rate constants of TPP prompt fluorescence quenching by $\mathrm{O}_{2}$ are noticeably smaller than the expected diffusion controlled one (see above) implying the noncomplete singlet excited state quenching by $\mathrm{O}_{2}$ during the lifetime of $\left(\mathrm{S}_{1},{ }^{3} \mathrm{O}_{2}\right)$ encounter complex in both solid and liquid samples.

The estimation of the $\alpha$ values for SOFDF in concentrated solid samples with small amounts of n-decanol gave values 3 times smaller as compared with those found in neat $\mathrm{n}$-decanol. This difference may reflect the changes in life-time and mutual orientation of reactants within $\left(\mathrm{S}_{1},{ }^{3} \mathrm{O}_{2}\right)$ primary couple at the interfaces, relative to these parameters in the bulk liquid. The rate constants $\mathrm{k}_{\mathrm{q}}^{1}$ extracted from concentrated solid samples with small amounts of n-decanol are approximately 4 times smaller than those in neat $n$-decanol which may be attributed to the trapping of singlet oxygen by TPP aggregates on the surface as it happened on gas/solid interface $[8,9]$.

\subsection{Acceleration of triplet-triplet annihilation by phase transition from liquid to polycrystalline $n$ -} decanol. An increase in the temperature of solid samples with $\mathrm{n}$-decanol as well as neat liquid n-decanol solution of TPP in the range $7-100{ }^{\circ} \mathrm{C}$ results in acceleration of direct TTA and in corresponding increase of TTADF initial intensity. The temperature plot of $\mathrm{k}_{\mathrm{OBS}}$ is described by the Arrhenius law with activation energy near $7 \mathrm{kcal} / \mathrm{mol}$ in neat n-decanol (Figure 5) and in the solid samples with large amount of n-decanol. This value is close to that of the viscous flow of $n$-decanol $(6.3 \mathrm{kcal} / \mathrm{mol})$ and confirms the diffusion control of TTA $[16,17]$. The TTA activation energy found in solid samples with small amount of $\mathrm{n}$-decanol corresponding

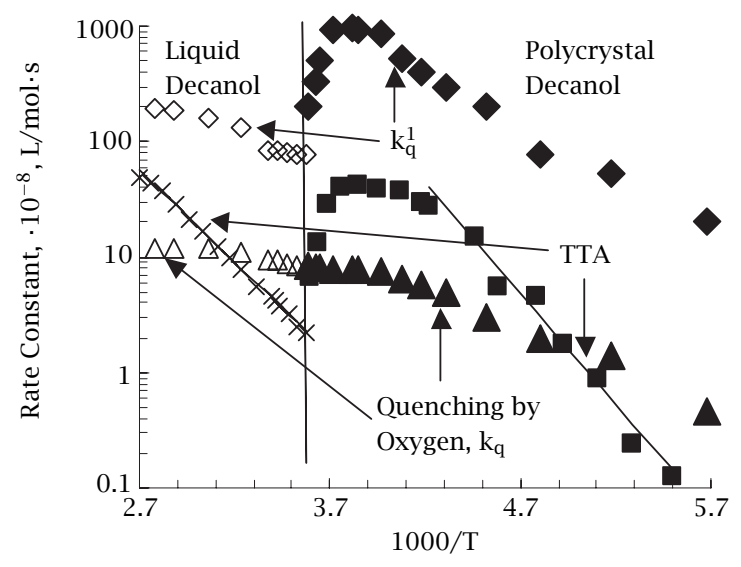

Figure 5. Arrhenius plots of apparent rate constants of TTA $(\times$ and $\mathbf{\square})$, quenching of TPP triplets by oxygen $(\triangle$ and $\Delta)$ and singlet-triplet energy transfer from singlet oxygen to TPP triplets $\left(\mathrm{k}_{\mathrm{q}}^{1}\right)(\diamond$ and $\diamond$ in liquid $(\times, \triangle$ and $\diamond)$ and frozen (ם, $\Delta$ and n-decanol. 
to $\leq 10-20$ monolayers is noticeably smaller than that in neat $n$-decanol demonstrating the specific features of diffusion at the liquid/solid interface [20].

In contrast, the kinetics of SOFDF and of oxygen quenching of ${ }^{3}$ TPP are not very sensitive to the temperature showing that oxygen diffusion in liquid n-decanol and at the liquid/solid interface is not controlled by ndecanol viscous flow. The yield of ${ }^{3} \mathrm{TPP}$ and parameters of prompt fluorescence and SOFDF are almost independent of the temperature.

A decrease in the temperature of neat n-decanol to $6{ }^{\circ} \mathrm{C}$ results in the freezing of $n$-decanol and formation of a light-scattering layered polycrystalline structure. The parameters of prompt fluorescence measured in diffuse reflectance mode almost coincide with those for the liquid solution measured with the same setup geometry and, as in the liquid solution, they are almost temperature independent down to $-100{ }^{\circ} \mathrm{C}$. Therefore the freezing has no effect on TPP photophysical characteristics and ${ }^{3}$ TPP yield, in particular. The TTADF relative yield remains virtually unchanged upon n-decanol freezing and, as in liquid n-decanol, is independent of the temperature of the frozen solution, indicating an unchanged TTA mechanism.

The retardation of bimolecular processes upon freezing is usually expected due to the restrictions of the translation molecular mobility in crystals as compared to liquid. However, the freezing of n-decanol in the solid samples with large amount of n-decanol as well as neat liquid n-decanol solution of TPP at melting point and further temperature decrease up to $-10{ }^{\circ} \mathrm{C}$ results in gradual acceleration of direct TTA and in corresponding increase of TTADF initial intensity (Figures 5 and 6). In n-decanol multilayers, this phase transition effect is observed at similar temperature as in neat n-decanol. Equations (1) and (2) describes the TTA and TTADF kinetics in frozen samples as good as that in liquid systems. The TTA apparent rate runs up to the maximum with temperature decrease to $-10^{\circ} \mathrm{C}$. The $\mathrm{k}_{\mathrm{OBS}}$ value at $-10^{\circ} \mathrm{C}$ exceeds more than tenfold the corresponding value measured at $10^{\circ} \mathrm{C}$. Further temperature decrease results in a relatively sharp retardation of TTA. The direction and rate of the temperature change and the freezing velocity have no pronounced effect on the corresponding temperature plots obtained in experiments where the thermostatic bath with temperature $\geq-50{ }^{\circ} \mathrm{C}$ was used.

The freezing results also in the acceleration of SOFDF rise time and in the increase of the SOFDF maximum intensity while the SOFDF decay part as well as the quenching of TPP triplets by oxygen is not sensitive to phase transition (Figure 6). Below the melting point of ndecanol, the temperature plot for singlet-triplet energy transfer rate constant $\mathrm{k}_{\mathrm{q}}^{1}$ extracted from parameter $\mathrm{k}_{\mathrm{q}}^{1}[\mathrm{~T}]_{0}$ obtained from fitting of SOFDF kinetic curves using equation (3) is similar to that for $\mathrm{k}_{\mathrm{OBS}}$ (Figure 6).

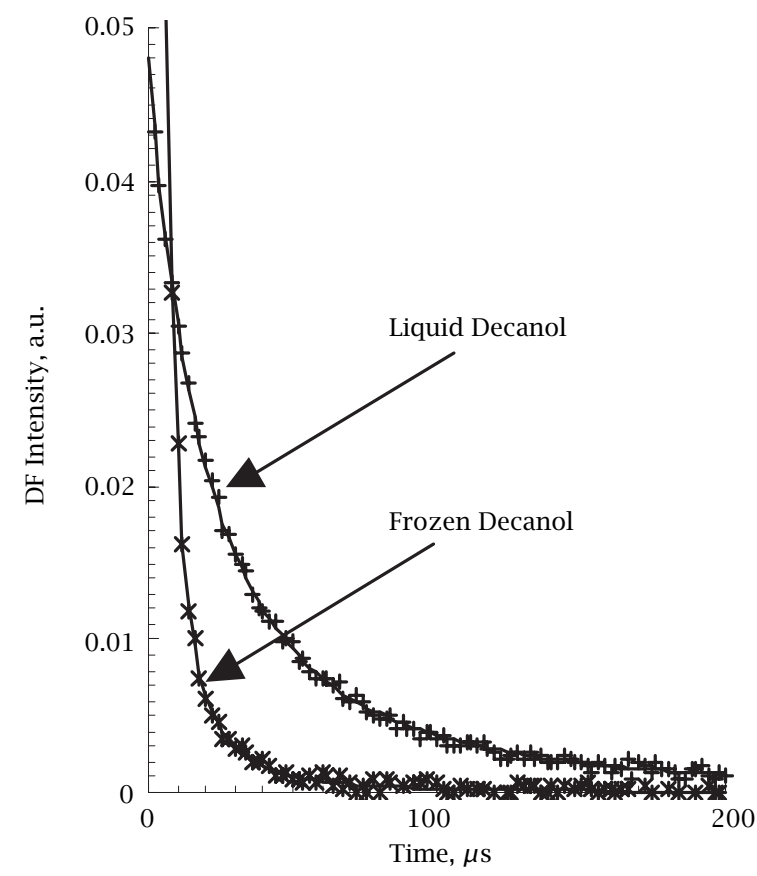

Figure 6. Decays of the transient emission at $720 \mathrm{~nm}$ measured with $0.01 \mu \mathrm{mol} / \mathrm{g} \mathrm{TPP}$ and $200 \mu \mathrm{L} / \mathrm{g}$-decanol in the deoxygenated solid NaA samples at 10 and $-20^{\circ} \mathrm{C}$.

Similar temperature plots were obtained earlier for the encounter frequency of $\mathrm{N}$-oxyl radicals in n-decane and benzene during the spin-probe ESR studies of the crystallization of liquids [21] as well as for TTA of TPP in benzene and aromatic alcohol [17]. It was assumed [21] that the effect is based on the concentration of dissolved organic molecules in some residual liquid domains in polycrystalline phase. Solvent crystallization is accompanied by the "extrusion" of the molecules of the dissolved substance from the nucleating crystal into the noncrystalline liquid-like defects at the interface of microcrystals. The fraction of liquid-like microphase in partially polycrystalline material and the probe translation mobility within it decrease with temperature. The maximum in the temperature plots of apparent TTA rate constant appears when the local TPP concentration and translation mobility are optimal. In all systems studied [16, 17, 21], it was observed at the temperature which is significantly lower than the melting point.

It is worthwhile mentioning that a formation of liquid-like microdomains in a partially polycrystalline matrix is not a result of freezing point depression due to the large organic probe local concentration. It still remains significantly smaller than that which is able to have noticeable affect the melting point [21]. This conclusion is strongly supported by the independence of temperature plots of the apparent TTA rate constant on TPP concentration varied in the range 
0.001-0.01 mmol/1 [16, 17]. The observed temperature dependent liquid-crystal equilibrium seems to be the specific property of some polycrystalline materials.

The kinetics of the bimolecular process in a frozen solution remains solely homogeneous. Frozen n-decanol does not exhibit kinetic polydispersity, which usually appears in solid media due to the nonuniform spatial distribution of reactants and heterogeneous molecular environment. The found value of the effect assumes a possibility to reach a very high local concentration of TPP (up to $0.1 \mathrm{~mol} / \mathrm{l}$ ), at which it is expected that TPP molecules should precipitate and aggregate, and corresponding pronounced variations of spectral and fluorescence parameters should be observed. However, the prompt fluorescence spectrum, lifetime and quantum yield for TPP in frozen n-decanol are very similar to those observed in liquid solution. The experimental data indicate the very high mobility of the porphyrin molecules in the regions of their localization in frozen n-decanol and the homogeneous nature of these regions. The surprisingly high solubility and mobility of TPP in liquid microreactors in polycrystalline media seems to be due to the presence of crystal/liquid interfaces. One can assume that the porphyrin molecules "slide" over the microcrystal surface in the available liquid-like volume.

The above speculations are supported by the results of temperature studies of TTA of TPP in the solid zeolite samples with small amount of n-decanol ( $\leq 10$ monolayers) [20]. In this case, there is no significant variation of the local concentration of TPP after n-decanol freezing. The apparent rate of TTA becomes practically temperature independent in the range 10$-20^{\circ} \mathrm{C}$ demonstrating the fast diffusion of TPP triplets on the surface of frozen n-decanol multilayer covering zeolite particles.

\section{CONCLUSION}

The kinetics of direct triplet-triplet annihilation and the same energy transfer between two organic triplets mediated by molecular oxygen are studied at gas/solid interface, at gas/liquid/solid system, in neat liquid and in frozen polycrystalline solution showed that liquid multilayers covering a solid surface and liquid domains in polycrystalline matrix may be used as a specific microreactors for bimolecular processes. A very large local concentration of reactants may be obtained using small bulk amounts. A high molecular mobility and surface induced molecular ordering at liquid/solid interface may supply possibilities which can be hardly achieved in homogeneous liquid media.

\section{ACKNOWLEDGMENTS}

This work was supported by the CQE- 4 and in part by JNICT (Project 2/21/QUI/443/94), and by the Russian Foundation for Basic Research (00-03-32190).

\section{References}

[1] D. Oelkrug, S. Uhl, F. Wilkinson, and C. J. Willsher, J. Phys. Chem. 93 (1989) 4551.

[2] D. Oelkrug, M. Gregor, and S. Reich, Photochem. Photobiol. 54 (1991) 539.

[3] F. Wilkinson, D. R. Worrall, and S. L. Williams, J. Phys. Chem. 99 (1995) 6689.

[4] R. F. Khairutdinov, P. P. Levin, and S. M. B. Costa, Langmuir 12 (1996) 714.

[5] P. P. Levin and S. M. B. Costa, J. Photochem. Photobiol. A Chem. 139 (2001) 167.

[6] P. P. Levin, S. M. B. Costa, L. F. V. Ferreira, J. M. Lopes, and F. R. Ribeiro, J. Phys. Chem B 101 (1997) 1355.

[7] P. P. Levin, S. M. B. Costa, J. M. Lopes, F. N. Serralha, and F. R. Ribeiro, Spectrochim. Acta A 56 (2000) 1745.

[8] P. P. Levin and S. M. B. Costa, Chem. Phys. Lett. 320 (2000) 194.

[9] P. P. Levin and S. M. B. Costa, Chem. Phys. 263 (2001) 423.

[10] J. K. Thomas, Chem. Rev. 93 (1993) 301.

[11] K. Hoffmann, F. Marlow, and J. Caro, Zeolites, 16 (1996) 281.

[12] T. H. Tran-Thi, J. F. Lipskier, P. Maillard, M. Momenteau, J.-M. Lopez-Castillo, and J.-P. Jay-Gerin, J. Phys. Chem. 96 (1992) 1073.

[13] L. Pekkarinen and H. Linschits, J. Am. Chem. Soc. 82 (1960) 2407.

[14] J. Rodriguez, C. Kirmaier, and D. Holten, J. Am. Chem. Soc. 111 (1989) 6500.

[15] G. P. Gurinovich and B. M. Jagarov, in Luminescence of Crystals, Molecules and Solutions, Plenum Press, New York, 1973, p. 196.

[16] P. P. Levin, Russ. Chem. Bull. 49 (2000) 1831.

[17] P. P. Levin, Dokl. Phys. Chem. 374 (2000) 187.

[18] M. Pineiro, A. L. Carvalho, M. M. Pereira, A. M. d'A. R. Gonsalves, L. G. Arnaut, and S. J. Formosinho, Chem. Eur. J. 4 (1998) 2299.

[19] T. L. C. Figueiredo, R. A. W. Johnstone, A. M. P. S. Sorensen, D. Burget, and P. Jacques, Photochem. Photobiol. 69 (1999) 517.

[20] P. P. Levin and S. M. B. Costa, in preparation.

[21] E. M. Mil, A. L. Kovarskii, and A. M. Vasserman, Izv. Akad. Nauk SSSR, Ser. Khim. 10 (1973) 2211. 


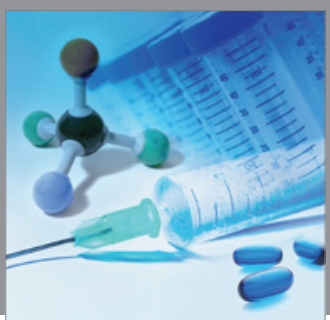

International Journal of

Medicinal Chemistry

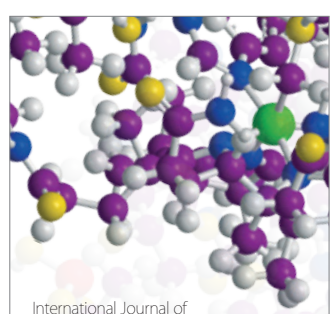

Carbohydrate Chemistry

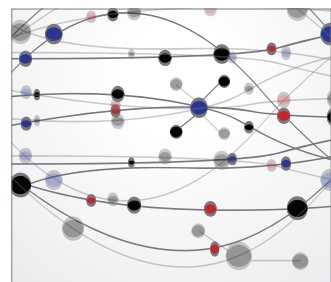

The Scientific World Journal
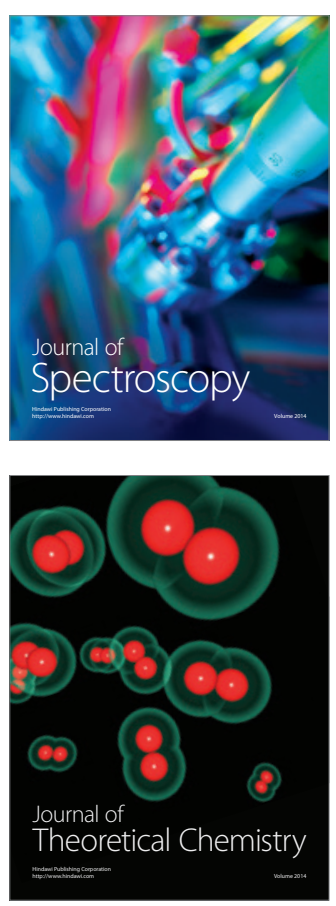
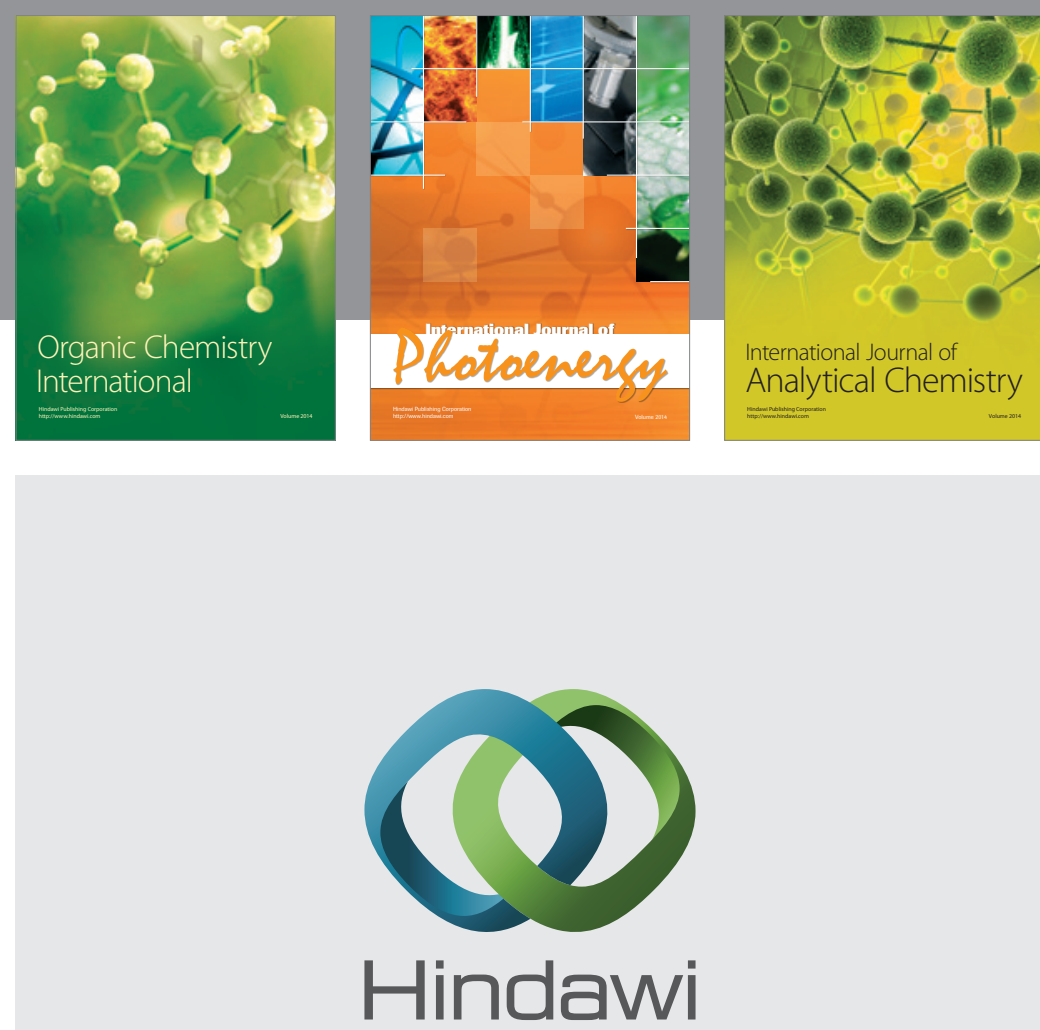

Submit your manuscripts at

http://www.hindawi.com
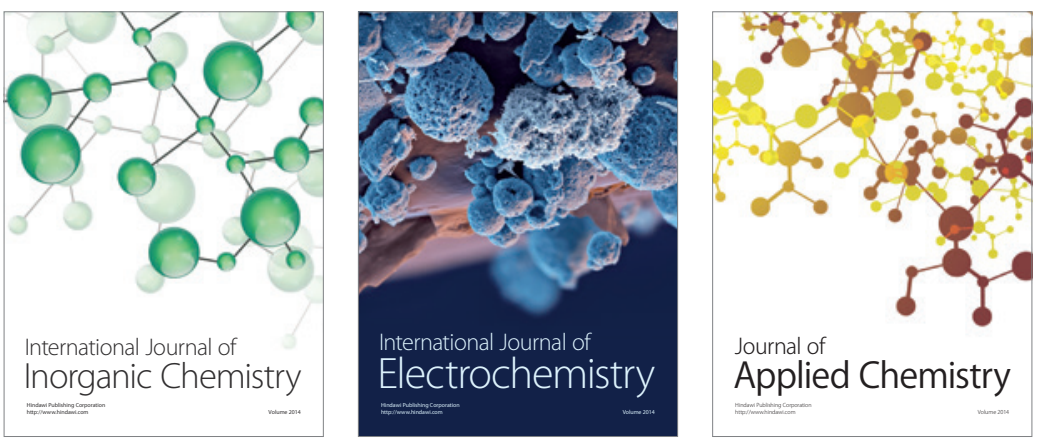

Journal of

Applied Chemistry
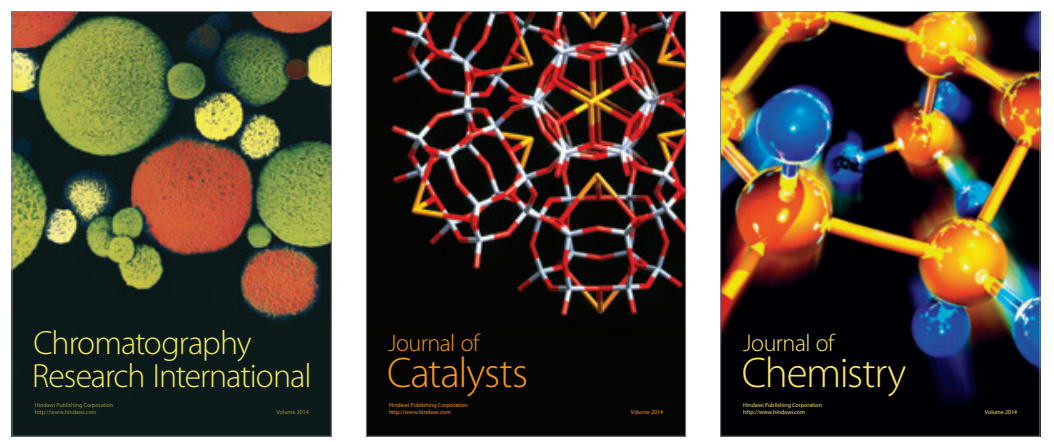
